\title{
Exploring the effect of remote substituents and solution structure on the luminescence of three lanthanide complexes
}

Manuel Tropiano, ${ }^{a}$ Octavia A. Blackburn, ${ }^{a}$ James A. Tilney, ${ }^{a}$ Leila R. Hill, ${ }^{a}$ Thomas Just Sørensen ${ }^{\mathrm{a}, \mathrm{b} *}$ and Stephen Faulkner ${ }^{\mathrm{a} *}$

a. Chemistry Research Laboratory, Oxford University, 12 Mansfield Road, Oxford OX1 3TA, UK, e-mail: stephen.faulkner@chem.ox.ac.uk, telephone: +44 1865285148.

b. Nano-Science Center \& Department of Chemistry, University of Copenhagen, Universitetsparken 5, 2100 København $\varnothing$, Denmark, e-mail: TJS@chem.ku.dk, telephone: +45 353202 13, fax: +45 3532 0214.

\section{Keywords}

We investigate kinetically inert lanthanide complexes; lanthanide emission; sensitised emission; lanthanide solvation; solution structure;

\section{Research Highlights}

- We investigate the effects of remote substituents on the luminescence from kinetically stable lanthanide complexes

- Molecular structure rather than chromophore density determines outcome of lanthanide sensitization

- Kimura's and Horrocks' approach to determine lanthanide solvation is revisited

- Solvent can significantly change sensitization pathways in multinuclear lanthanide complexes

- Increasing chromophore density may reduce the amount of lanthanide luminescence observed

\section{Abstract}

Sensitized luminescence from trivalent lanthanide ions relies on an appropriate match of energy between the sensitizer's excited state (triplet or singlet) and the lanthanide excited state manifold and an efficient mechanism of energy transfer between the two. Here, the effect of remote substituents on the luminescence properties of a series of related lanthanide complexes has been investigated. The sensitized lanthanide centered emission is found not to occur following excitation of all chromophores in all systems, and it is shown that only the most complicated of the systems investigated exhibited pronounced solvatochromism.

\section{Introduction}

While the electronic transitions between the electronic states of lanthanide ions are characterized in the solid state, and in well-defined geometries,[1-8] our understanding of the photophysical properties of lanthanide ions and lanthanide complexes in solution is limited to describing the simplest and most symmetric complexes.[9-15] This is a direct consequence of the long luminescence lifetime of the trivalent 
lanthanide ions, which in combination with the fast exchange of simple ligands by these ions,[16] makes the emission detected from any solution-based experiment a weighted average. Constitutional isomers aside, even conformational isomers may have different properties, which make it a big challenge to produce data that can be correlated to a single lanthanide species. Three approaches to meet this challenge can be adopted: 1 ) synthesis of lanthanide complexes that are locked displaying only a single species and a single conformation in solution; 2 ) synthesis of large quantities of ultrapure complexes that can be used to perform absorption based experiments; 3 ) synthesis of complicated molecular structures that can be used to probe the structure-property relationships in lanthanide complexes indirectly.

We recently demonstrated the synthesis of a range of multinuclear lanthanide complexes using the Ugi reaction, 'click' chemistry, and peptide coupling reactions to link kinetically stable building blocks together, [17-21] and observed for the first time that changes to substituents remote from the binding site could have a profound effect on the affinity of these complexes for anionic guests.[22] Here, we continue the investigation into these systems, establishing the photophysical properties of these multinuclear lanthanide complexes in detail, and elucidating key information about the role of structure and solvent in determining their solution structure.

Due to the very low molar absorptivity of the $f$ - $f$ transitions, direct excitation of lanthanide centered transitions are inefficient.[23, 24] Therefore, sensitizing chromophores are used to generate lanthanide centered excited states. This process is called the antenna effect, see Figure 1. Instead of direct excitation of the lanthanide, light is absorbed by a chromophore with a high molar absorptivity, generating an excited state that is able to populate the lanthanide centered excited state via an appropriate energy transfer process. While the efficiency of the energy transfer is not unity, the lanthanide excited state population generated following irradiation is still multiple times that which would be obtained following excitation directly into the $f$-manifold using irradiation of similar intensity. Here, we show how important the spatial relationship between lanthanide center and the sensitizing chromophore can be in determining the observed emission intensity, by comparing two similar trinuclear (and a bimetallic) lanthanide complexes. From these results, it will be seen that an increased chromophore density alone does not make for highly luminescent lanthanide complexes, as not all lanthanide centers in the investigated molecules are populated efficiently by the chromophores in the structure.

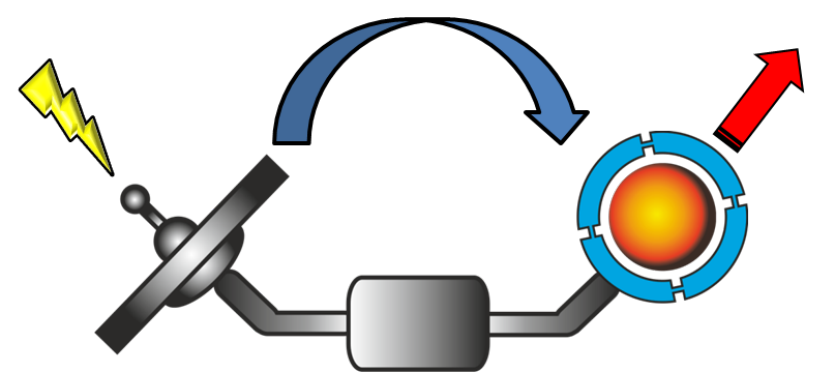




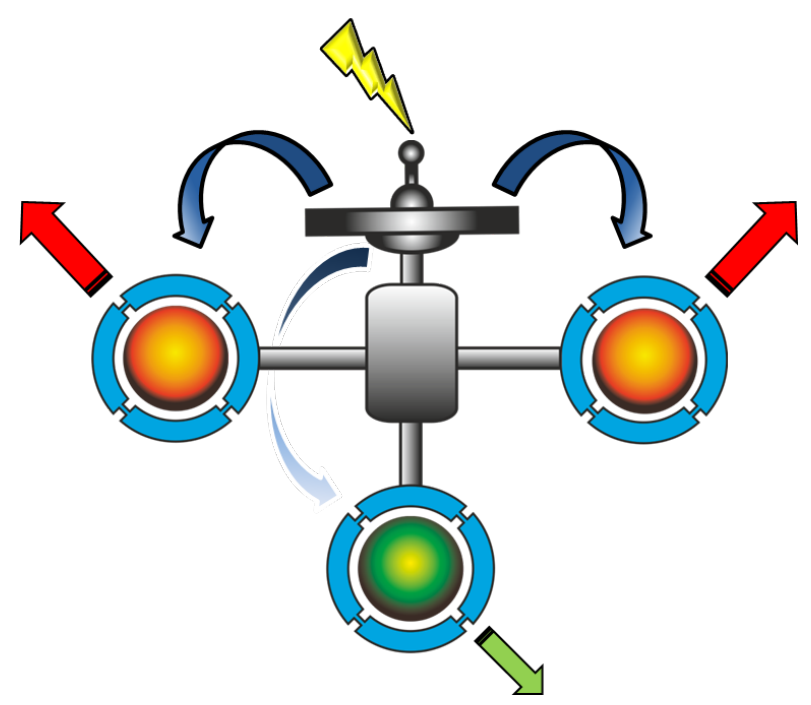

Figure 1. Cartoon showing sensitized population of lanthanide centered excited states in simple mononuclear complexes (top) and in multinuclear heterometallic complexes (bottom).

\section{Methods and materials}

\section{Materials}

All materials were used as received; solvents were of HPLC grade and were used without further purification. The molecules investigated were prepared as described in ref.[22]

\section{Spectroscopy}

Spectroscopy was performed using conventional absorption (Agilent Cary 300/PerkinElmer Lambda1050) and emission spectrometers (Agilent Cary Eclipse/Horiba Fluorolog) and $1 \mathrm{~cm}$ quartz cuvettes (Helma). Time-gating and phosphorescence spectra were recorded by applying a delay time and subsequently recording over a suitable time-window. The time-resolved emission spectra (TRES) were produced by increasing the delay time and keeping the time-window constant. Luminescence lifetimes were determined using the same method and at a single wavelength in the spectrum.

\section{Calculations of $q$ - the number of inner sphere solvent molecules}

It has been recognized that lanthanide excited states can be quenched by transferring energy to overtones of molecular vibrations, $[24,25]$ and it was found that the $\mathrm{OH}$ stretching vibration is an effective energy acceptor for energy transfer from a lanthanide excited state.[26] As the rate of energy transfer is strongly distance dependent $\left(\mathrm{k}_{\mathrm{ET}} \propto \mathrm{r}^{-6}\right),[27,28]$ the degree of quenching of a lanthanide centered excited state can be used to calculate the number of molecules containing $\mathrm{OH}$ oscillators that are bound to the lanthanide center. This was realized by Horrocks, who developed a method to determine $q$ - the number of water molecules bound at a lanthanide center.[26] The Horrocks equation in its native and modified form is described below. Another approach to use the quenching of lanthanide excited states by $\mathrm{OH}$ oscillators was developed by Kimura.[29] The foundation for the Kimura approach, discussed below, is significantly different from that of the Horrocks equation.

Each approach uses the observed luminescence lifetime $\tau_{L M}$ to determine $q$. The luminescence lifetime can be related to the rate constant for depopulating the excited state $k_{o b s}$, with $\tau_{L M}{ }^{-1}=k_{o b s}$. The observed rate constant is the sum of processes depopulating the lanthanide excited state (eq. 1), where the most important contributions are: 
- $\mathrm{k}_{\mathrm{r}}$ radiative decay from the lanthanide excited state

- $\mathrm{k}_{\mathrm{nr}}$ non-radiative decay from the lanthanide excited state, a sum of a series of quenching processes:

- $\mathrm{k}_{\mathrm{OH}}$ quenching by $\mathrm{OH}$ oscillators of inner-sphere solvent molecules, note that a single water molecule has two $\mathrm{OH}$ oscillators whereas e.g. alcohols have one $\mathrm{OH}$ oscillator; the degree of quenching is proportional to the number of oscillators and not the number of solvent molecules

- $\mathrm{k}_{\mathrm{NH}}$ quenching by $\mathrm{NH}$ oscillators in close proximity to the lanthanide center that can undergo deuterium exchange, not necessarily coordinated

- $\mathrm{k}_{\text {ligand }}$ quenching by specific ligand structures, not $\mathrm{OH}$ or $\mathrm{NH}$ oscillators

- $\mathrm{k}_{\text {other }}$ quenching from other contributions such as solvated ions, outer sphere solvent $\left(k_{\text {outer }}\right)$ etc.

The radiative decay constant $\mathrm{k}_{\mathrm{r}}$ is the sum of all the radiative processes depopulating the excited state of a given lanthanide i.e. a sum over seven independent processes for terbium and europium, while the nonradiative decay constant $k_{n r}$ is dominated by the listed contributions in the absence of specific quenching pathways such as electron transfer in europium and ytterbium and energy back-transfer to low lying chromophore states.

\section{Horrocks equation}

In order to evaluate the effect of solvent induced quenching of lanthanide excited states, the observed luminescence lifetime can be used by considering the following relationships:

(1) $\tau_{\mathrm{LM}}^{-1}=\mathrm{k}_{\mathrm{obs}}=\mathrm{k}_{\mathrm{r}}+\mathrm{k}_{\mathrm{nr}}=\mathrm{k}_{\mathrm{r}}+\mathrm{k}_{\text {ligand }}+\mathrm{k}_{\mathrm{OH}}+\mathrm{k}_{\mathrm{NH}}+\mathrm{k}_{\mathrm{other}}$

(2) $\tau_{\mathrm{LM}}\left(\mathrm{H}_{2} \mathrm{O}\right)^{-1}=\mathrm{k}_{\mathrm{obs}}^{\mathrm{H}}=\mathrm{k}_{\mathrm{r}}+\mathrm{k}_{\text {ligand }}+\mathrm{k}_{\mathrm{OH}}+\mathrm{k}_{\mathrm{NH}}+\mathrm{k}_{\text {other }}$

(3) $\tau_{L M}\left(D_{2} O\right)^{-1}=k_{\text {obs }}^{D}=k_{r}+k_{\text {ligand }}+k_{N H}+k_{\text {other }}$

(4) $\tau_{\mathrm{LM}}\left(\mathrm{H}_{2} \mathrm{O}\right)^{-1}-\tau_{\mathrm{LM}}\left(\mathrm{D}_{2} \mathrm{O}\right)^{-1}=k_{\mathrm{F}}+k_{\text {Higand }}+k_{\mathrm{OH}}+k_{\text {AH }}+k_{\text {oter }}-k_{f}-k_{\text {Higand }}-k_{\text {HH }}-k_{\text {other }}=k_{\text {obs }}^{\mathrm{H}}-k_{\text {obs }}^{\mathrm{D}}=\Delta \mathrm{k}_{\mathrm{obs}}=k_{\mathrm{OH}}$

(5) $k_{\mathrm{OH}}=k_{\mathrm{OH}}^{1}+k_{\mathrm{OH}}^{2}+k_{\mathrm{OH}}^{3} \ldots+k_{\mathrm{OH}}^{n}$ if $\mathrm{k}_{\mathrm{OH}}^{1}=k_{\mathrm{OH}}^{n}$ then $k_{\mathrm{OH}}=n k_{\mathrm{OH}}^{\prime}$

(6) $n k^{\prime} \mathrm{OH}^{\prime}=\Delta \mathrm{k}_{\mathrm{obs}}=\tau_{\mathrm{LM}}\left(\mathrm{H}_{2} \mathrm{O}\right)^{-1}-\tau_{\mathrm{LM}}\left(\mathrm{D}_{2} \mathrm{O}\right)^{-1}$

(7) $n=\left(\mathrm{K}_{\mathrm{OH}}^{\prime}\right)^{-1}\left(\tau_{\mathrm{LM}}\left(\mathrm{H}_{2} \mathrm{O}\right)^{-1}-\tau_{\mathrm{LM}}\left(\mathrm{D}_{2} \mathrm{O}\right)^{-1}\right)$

Assuming that only inner-sphere $\left(\mathrm{k}_{\mathrm{O}}\right)$ solvent is responsible for reduced quenching between $\mathrm{H}$ and $\mathrm{D}$, if $\mathrm{A}=$ $\left(\mathrm{k}_{\mathrm{OH}}^{\prime}\right)^{-1}$ and $n=q$ then the Horrocks equation is obtained:[26]

(8) $q=\mathrm{A}\left(\tau_{\mathrm{LM}}\left(\mathrm{H}_{2} \mathrm{O}\right)^{-1}-\tau_{\mathrm{LM}}\left(\mathrm{D}_{2} \mathrm{O}\right)^{-1}\right)$

If more contributions are present, then:

(9) $\tau_{L M}\left(\mathrm{H}_{2} \mathrm{O}\right)^{-1}-\tau_{L M}\left(\mathrm{D}_{2} \mathrm{O}\right)^{-1}=\mathrm{k}_{\text {obs }}^{\mathrm{H}}-\mathrm{k}_{\text {obs }}^{\mathrm{D}}=\Delta \mathrm{k}_{\text {obs }}=\mathrm{k}_{\mathrm{OH}}+\mathrm{k}_{\mathrm{NH}}+\mathrm{k}_{\text {outer }}=n \mathrm{k}_{\mathrm{OH}}^{\prime}+\mathrm{k}_{\mathrm{NH}}+\mathrm{k}_{\text {outer }}$

(10) $n k_{\mathrm{OH}}^{\prime}=\tau_{\mathrm{LM}}\left(\mathrm{H}_{2} \mathrm{O}\right)^{-1}-\tau_{\mathrm{LM}}\left(\mathrm{D}_{2} \mathrm{O}\right)^{-1}-\mathrm{k}_{\mathrm{NH}}-\mathrm{k}_{\text {outer }}$

(11) $n=\left(\mathrm{k}_{\mathrm{OH}}^{\prime}\right)^{-1}\left(\tau_{\mathrm{LM}}\left(\mathrm{H}_{2} \mathrm{O}\right)^{-1}-\tau_{L M}\left(\mathrm{D}_{2} \mathrm{O}\right)^{-1}-\mathrm{k}_{\text {outer }}-\mathrm{k}_{\mathrm{NH}}\right)$

If $\mathrm{A}=\left(\mathrm{k}_{\mathrm{OH}}^{\prime}\right)^{-1}, \mathrm{~B}=\mathrm{k}_{\text {outer }}, \mathrm{C}=\mathrm{k}_{\mathrm{NH}}$ and $n=q$ then the modified Horrocks equation is obtained:[15]

(12) $q=\mathrm{A}\left(\tau_{\mathrm{LM}}\left(\mathrm{H}_{2} \mathrm{O}\right)^{-1}-\tau_{\mathrm{LM}}\left(\mathrm{D}_{2} \mathrm{O}\right)^{-1}-\mathrm{B}-\mathrm{C}\right)$ 
The main assumptions in this approach are that each $\mathrm{OH}$ oscillator in the inner coordination sphere induces the same rate of quenching in all complexes and solvates (eq. 5), that the solvent in the outer sphere gives rise to the same rate of quenching in all complexes and solvates (eq. 10), and that the distances to amino/amido quenchers and $\mathrm{OH}$ oscillators are similar for all complexes and solvates. As a consequence, the modified Horrocks equation should be applied with a degree of skepticism and $q$ should not be given with more than two significant figures. Note that the error when using the Horrocks equation/modified Horrocks equation is $q+/-0.5$ (solvent molecules), while smaller differences can be considered significant when similar ligand structures are compared under identical experimental conditions.

$\mathrm{k}_{\text {ligand }}$ can be ignored if no units known to quench lanthanide excited states are present - note that $\mathrm{OH}$ and $\mathrm{NH}$ oscillators have already been accounted for. For neodymium, praseodymium, and erbium, $\mathrm{C}-\mathrm{H}$ oscillators have been shown to provide an effective pathway for non-radiativ quenching of the lanthanide excited state. For these lanthanides, ligand oscillators must also be taken into account when targeting highly luminescent compounds.[30-33] Generally the actual ligand structure has to be considered in order to determine $k_{\text {ligand. }}[30,34]$ As the additional quenching pathways are inherent to the molecular structure and thus independent of deuteration in the solvent, they have no effect when calculating hydration.

Kimura method

Using eq. 6 to rewrite eq. 1 , the following equations can be written:

(13) $\tau_{L M}\left(\mathrm{H}_{2} \mathrm{O}\right)^{-1}=\mathrm{k}^{\mathrm{H}}{ }_{\mathrm{obs}}=\mathrm{k}_{\mathrm{r}}+\mathrm{k}_{\text {ligand }}+\mathrm{k}_{\mathrm{OH}}+\mathrm{k}_{\mathrm{NH}}+\mathrm{k}_{\mathrm{other}}=n \mathrm{k}_{\mathrm{OH}}^{\prime}+\chi$

(14) $n=\left(\mathrm{k}_{\mathrm{OH}}^{\prime}\right)^{-1}\left(\tau_{\mathrm{LM}}\left(\mathrm{H}_{2} \mathrm{O}\right)^{-1}-\chi\right)=\left(\mathrm{k}_{\mathrm{OH}}^{\prime}\right)^{-1}\left(\tau_{\mathrm{LM}}\left(\mathrm{H}_{2} \mathrm{O}\right)^{-1}\right)-\left(\mathrm{k}_{\mathrm{OH}}^{\prime}\right)^{-1} \chi$

Kimura has been using experimental data to determine $\left(\mathrm{K}_{\mathrm{OH}}^{\prime}\right)^{-1}$ and $\left(\mathrm{K}_{\mathrm{OH}}^{\prime}\right)^{-1} \chi$ by measuring the excited state lifetimes in $\mathrm{H}_{2} \mathrm{O} / \mathrm{D}_{2} \mathrm{O}$ mixtures.[29, 35-40] This approach relies strongly on the assumption that all contributions except $n k_{\text {он }}$ are constants. As this can only be true for very similar ligand structures, the scope of this approach is limited. When considering more elaborate lanthanide and actinide complexes, the Horrocks equation must be used. The Horrocks equation uses the comparison of two independent measurements to reduce the uncertainties enforced by the required assumptions.

\section{Results and discussion}

Three different molecular structures 1-3 were investigated, while data for a fourth structure $\mathbf{4}$ is included for comparison. The molecular structures are shown in Chart 1. $\alpha, \alpha^{\prime}$-bis(Eu.DO3A)-m-xylene $(1, m$ bis(europium 1,4,7,10-tetraazacyclododecane-1,4,7-triacetate-10-methylene)-benzene) is a dinuclear europium complex, where each lanthanide is bound in a heptadentate binding pocket. In this molecular structure a single aniline chromophore is present. Compound $\mathbf{2}$ is derived from $\mathbf{1}$ by a peptide coupling with 4 (terbium 2,2',2"-(10-(2-((carboxymethyl)amino)-2-oxoethyl)-1,4,7,10-tetraazacyclododecane-1,4,7triyl)triacetate) which is a kinetically stable terbium DO3A-monoamide complex with a free carboxylic acid. $\mathbf{2}$ is a trinuclear heterobimetallic lanthanide complex, but as with $\mathbf{1}$ there is only one chromophore in the system. Where the chromophore in $\mathbf{1}$ is an aniline, in $\mathbf{2}$ the chromophore is an anilide. Thus, the chromophore density as well as position is identical in $\mathbf{1}$ and $\mathbf{2}$. Compound $\mathbf{3}$ is derived from $\mathbf{1}$ via an Ugi reaction with benzaldehyde, $\mathbf{4}$ and benzyl isonitrile. As with 2, $\mathbf{3}$ is a trinuclear heterobimetallic lanthanide complex, but with two phenyl rings in addition to the anilide chromophore. These make the overall structure of $\mathbf{3}$ significantly more crowded than that of $\mathbf{1}$ and $\mathbf{2}$. The position of the two additional chromophores in $\mathbf{3}$ is not fixed relative to the lanthanide centers, and conformations where there are sensitizers close to either of the three lanthanide centers are possible. While the distance from the anilide to each of the europium centers is identical, the chromophore to terbium distance is unlikely to be identical 
in all complexes 1-3. As there is no conjugation between chromophores and the lanthanide centers, the energy transfer to the lanthanide centers must be through space and thus mediated by intramolecular collisions. Therefore, the energy transfer and sensitization efficiency in $\mathbf{3}$ will depend greatly upon the molecular solution structure; in particular the conformational freedom of the two phenyl groups will be reflected in the luminescence properties of $\mathbf{3}$.

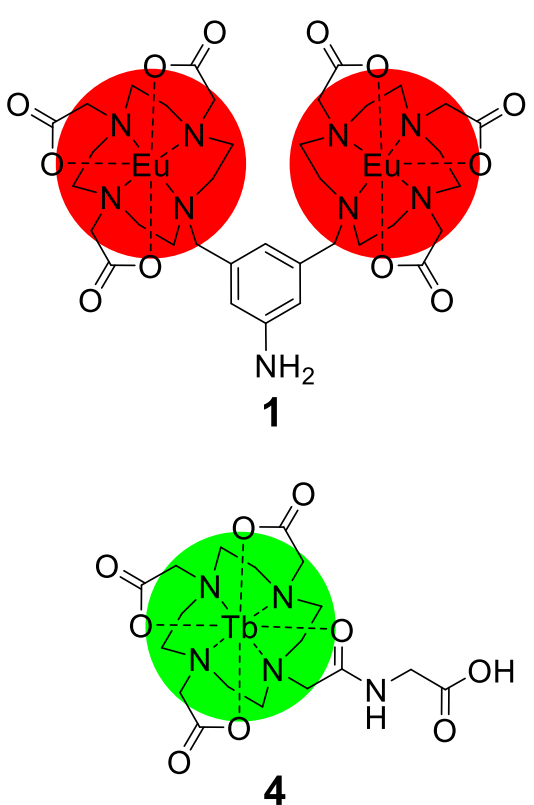

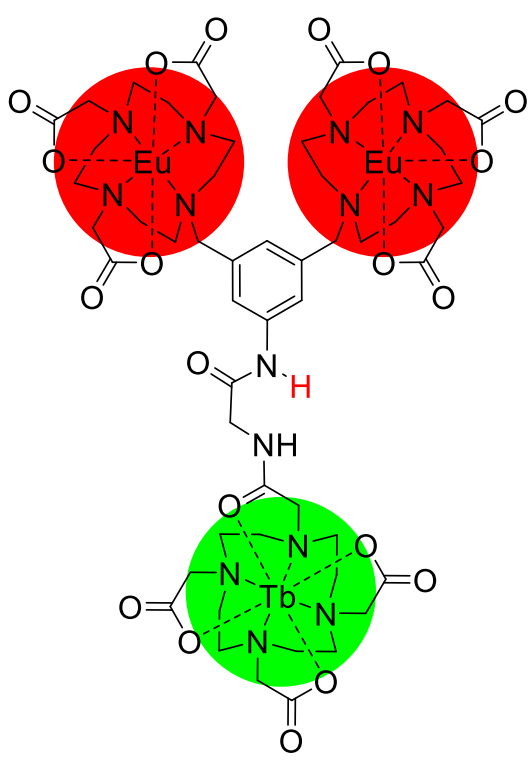

2

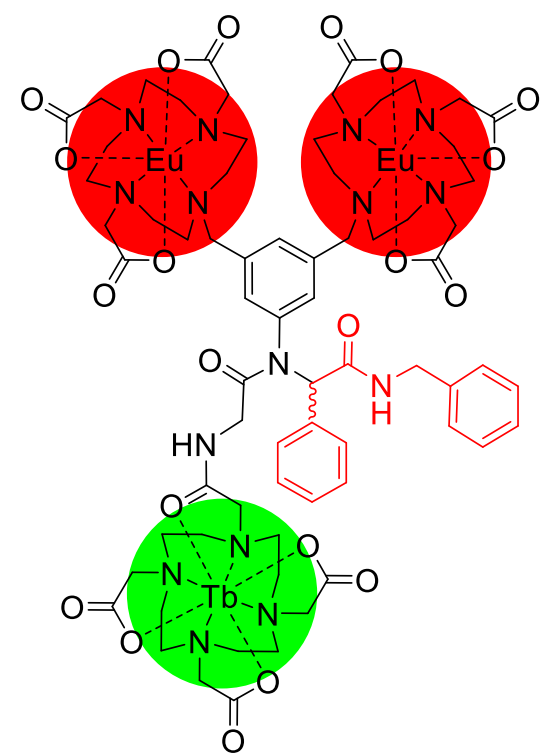

3

Chart 1. Molecular structures studied in this work.

The normalized absorption spectra of compounds 1-3 in $\mathrm{D}_{2} \mathrm{O}$ are shown in Figure 2. Ideally, the spectra should be a simple superposition of the component spectra, but this is not the case. In particular, the blueshift commonly observed between the spectra of aniline and acetanilide is not seen in the spectra of $\mathbf{2}$ and 3. This suggests that the molecular constitution inhibits the formation of the ideal, fully conjugated conformation of the acetanilide moiety in both $\mathbf{2}$ and 3.[27] Comparison of the spectra of $\mathbf{2}$ and $\mathbf{3}$ reveals an increased absorption in $\mathbf{3}$ at wavelengths below $325 \mathrm{~nm}$, which can be attributed to the introduction of the two phenyl groups.

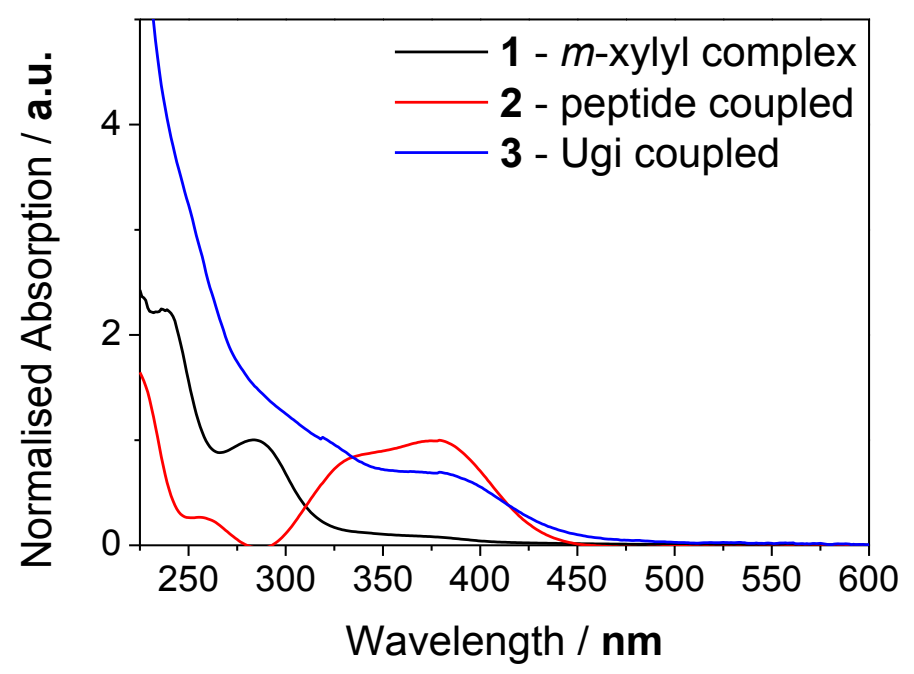


Figure 2. Normalized absorption spectra of $\mathbf{1 , 2}$ and $\mathbf{3}$ recorded in $\mathrm{D}_{2} \mathrm{O}$. The spectra are normalized by the intensity at the peak of the primary absorption band (1 $280 \mathrm{~nm} ; \mathbf{2} 390 \mathrm{~nm} ; \mathbf{3} 360 \mathrm{~nm}$ ).

\section{Luminescence spectra}

The normalized time-gated emission spectra of compounds $\mathbf{2}$ and $\mathbf{3}$ in acetonitrile, methanol, and $\mathrm{D}_{2} \mathrm{O}$ are shown in Figure 3. The spectrum of $\mathbf{2}$ shows emission bands that can be readily assigned to originate from lanthanide centered emission at the terbium and europium centers. Where the emission band at $488 \mathrm{~nm}$ $\left(\mathrm{Tb}^{5} \mathrm{D}_{4} \rightarrow{ }^{7} \mathrm{~F}_{6}\right)$ and $545 \mathrm{~nm}\left(\mathrm{~Tb}^{5} \mathrm{D}_{4} \rightarrow{ }^{7} \mathrm{~F}_{5}\right)$ are readily assigned to originate at the terbium center, the bands in the region 580-600 nm ( $\left(\mathrm{Tb}^{5} \mathrm{D}_{4} \rightarrow{ }^{4} \mathrm{~F}_{4}, \mathrm{Eu}{ }^{5} \mathrm{D}_{0} \rightarrow{ }^{7} \mathrm{~F}_{0,1}\right)$ and at $620 \mathrm{~nm}\left(\mathrm{~Tb}^{5} \mathrm{D}_{4} \rightarrow{ }^{7} \mathrm{~F}_{3}, \mathrm{Eu}^{5} \mathrm{D}_{0} \rightarrow{ }^{7} \mathrm{~F}_{2}\right)$ are a mixture of photons from each lanthanide center. The low intensity bands $\left(\mathrm{Tb}^{5} \mathrm{D}_{4} \rightarrow{ }^{7} \mathrm{~F}_{2,1,0}\right.$, Eu $\left.{ }^{5} \mathrm{D}_{0} \rightarrow{ }^{7} \mathrm{~F}_{3}\right)$ are not readily resolved in the time-gated emission spectrum of $\mathbf{2}$ following excitation at $280 \mathrm{~nm}$, while the band at $700 \mathrm{~nm}\left(\mathrm{Eu}^{5} \mathrm{D}_{0} \rightarrow{ }^{4} \mathrm{~F}_{4}\right)$ can unambiguously be assigned to europium. Comparing the emission intensity in the two bands from Eu ${ }^{5} \mathrm{D}_{0} \rightarrow{ }^{7} \mathrm{~F}_{4}(700 \mathrm{~nm})$ and Tb ${ }^{5} \mathrm{D}_{4} \rightarrow{ }^{7} \mathrm{~F}_{5}(545 \mathrm{~nm})$ allows for a direct measure of the relative population of the two lanthanide centers following excitation in the chromophore manifold. Direct excitation of terbium is possible by addressing the $\mathrm{Tb}^{5} \mathrm{D}_{4} \rightarrow{ }^{7} \mathrm{~F}_{6}$ transition at $488 \mathrm{~nm}$, but yielded no further information. Direct excitation of europium was not possible, as exciting the Eu ${ }^{7} \mathrm{~F}_{0} \rightarrow{ }^{5} \mathrm{~L}_{6}$ also resulted in excitation of the $\mathrm{Tb}^{5} \mathrm{D}_{4} \rightarrow{ }^{5} \mathrm{G}_{6}$ transition.[10, 11] The time-gated emission spectra of 2 in acetonitrile, methanol and $\mathrm{D}_{2} \mathrm{O}$ show no clear solvent dependence in the formation of the lanthanide excited states. Though, the relative intensities of the bands resulting from terbium centered transitions changes slightly, thus indicating a solvent dependence in the branching ratios observed in the emission from $\mathrm{Tb}^{5} \mathrm{D}_{4}$. That is, the $488 \mathrm{~nm}\left(\mathrm{~Tb}^{5} \mathrm{D}_{4} \rightarrow{ }^{7} \mathrm{~F}_{6}\right)$ band changes $10 \%$ in intensity when compared to the 545 $\mathrm{nm}\left(\mathrm{Tb}^{5} \mathrm{D}_{4} \rightarrow{ }^{7} \mathrm{~F}_{5}\right)$ band. For these,[17, 22] and related molecular structures, [41] we did not observe any effect of concentration on the excited state properties. Particularly the napthanlene containing complexes should be able to report on aggregation through excimer formation,[42] as this is not observed even at $\mathrm{mM}$ concentration we conclude that aggregation is not a factor for the complexes studied here. 


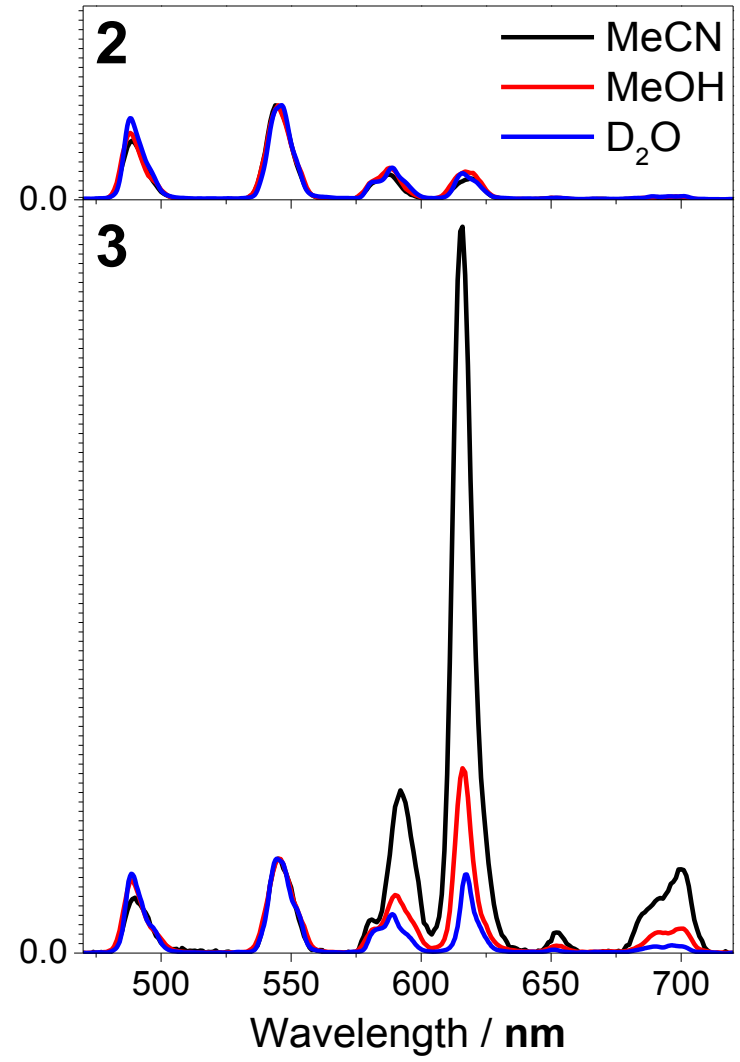

Figure 3. Normalized luminescence emission spectra of $\mathbf{2}$ and $\mathbf{3}$ recorded with a $5 \mathrm{~nm}$ emission slit following $280 \mathrm{~nm}$ excitation (excitation slit: $20 \mathrm{~nm}$, delay: $0.2 \mathrm{~ms}$, window: $3 \mathrm{~ms}$ ). The spectra are on the same scale and are normalized at $545 \mathrm{~nm}$.

The time-gated emission spectra of $\mathbf{3}$ following excitation at $280 \mathrm{~nm}$ are shown in Figure 3. Comparing the spectra of $\mathbf{2}$ and $\mathbf{3}$ in $\mathrm{D}_{2} \mathrm{O}$, there is a pronounced difference in the europium emission observed as the relative intensity observed in the Eu ${ }^{5} D_{0} \rightarrow{ }^{7} F_{4}$ band at $700 \mathrm{~nm}$ in $\mathbf{3}$ is twice that of $\mathbf{2}$ when measured relative to the terbium centered emission. This increase can be rationalized by assuming that the anilide chromophore preferentially populates the terbium excited state, while the two phenyl chromophores increase the population of the europium excited state. The branching ratio observed for terbium as a function of the changing solvent for $\mathbf{3}$ was similar to that observed for $\mathbf{2}$. The changes in relative emission intensities of europium and terbium when the solvent is changed from $\mathrm{D}_{2} \mathrm{O}$ to methanol and acetonitrile are dramatic. The relative intensity of the europium emission increases ten-fold when the solvent is changed from $\mathrm{D}_{2} \mathrm{O}$ to acetonitrile, while the luminescence lifetime is reduced (see below).

The differences in absorption and emission spectra are supported by the excitation spectra shown in Figure 4. The excitation spectra measured by monitoring terbium centered emission at $545 \mathrm{~nm}\left(\mathrm{~Tb}^{5} \mathrm{D}_{4} \rightarrow{ }^{7} \mathrm{~F}_{5}\right)$ are identical in $\mathbf{2}$ and $\mathbf{3}$, while there is a pronounced difference in the excitation spectra measured by monitoring europium centered emission at $690 \mathrm{~nm}\left(\mathrm{Eu}^{5} \mathrm{D}_{0} \rightarrow{ }^{7} \mathrm{~F}_{4}\right)$. From cursory inspection of the excitation spectra it would appear that europium is preferentially populated via the anilide chromophore in both $\mathbf{2}$ and $\mathbf{3}$, while there is no significant population of the terbium excited state from the two phenyl chromophores in $\mathbf{3}$. This outcome is related to our recent observations for a pyrene appended europium 
complex, where the separation between the europium center and the pyrene chromophore determined whether the lanthanide centered excited state could be populated from the pyrene triplet state.[43]

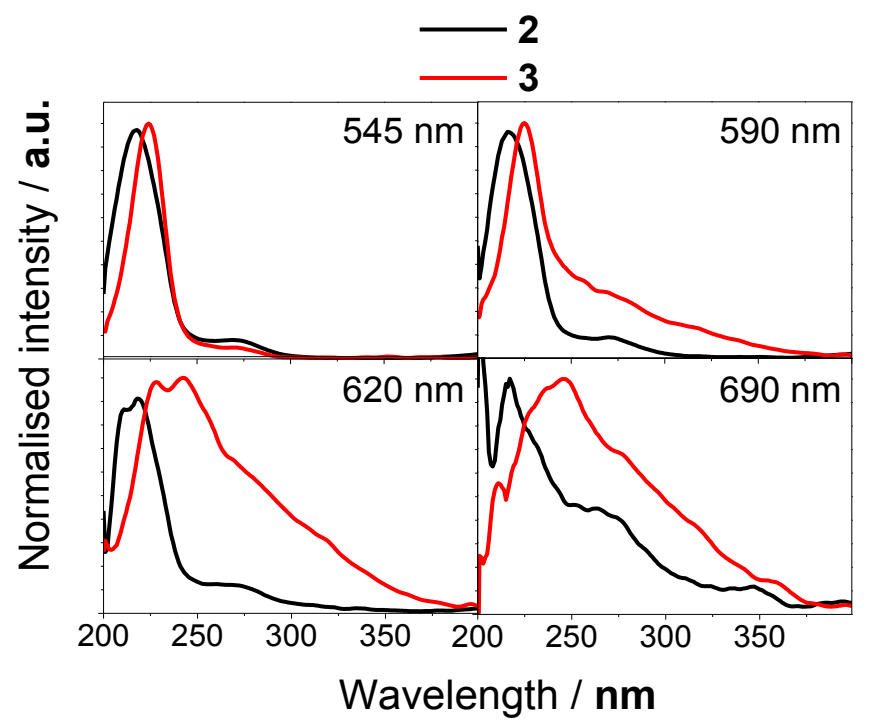

Figure 4. Normalized luminescence excitation spectra of $\mathbf{2}$ and $\mathbf{3}$ in $\mathrm{D}_{2} \mathrm{O}$ recorded with $10 \mathrm{~nm}$ slits at different points of observation (emission slit: $10 \mathrm{~nm}$, delay: $0.2 \mathrm{~ms}$, window: $3 \mathrm{~ms}$ ).

\section{Time-resolved emission spectra}

By exploiting the differences in luminescence lifetime, the time-resolved emission spectra (TRES) can separate signals originating at different emitters, thus efficiently removing background emission originating from sample background, chromophore centered emission and any endogenous or non-endogenous fluorophores in the system such as flavins.[44, 45] If the luminescence lifetimes of the individual emitters are spaced suitably, the pure emission spectra of overlapping species can be resolved, providing a third dimension (intensity, wavelength, time) to the detection in time-gated emission based experiment. Figure 5 shows the time-resolved emission spectra of $\mathbf{2}$ and $\mathbf{3}$. For $\mathbf{2}$ the TRES shows that the intensity distribution between terbium and europium centered emissions mirror that observed in the luminescence spectrum (Figure 3), and due to the slow $>1$ ms decay of the terbium emission, this dominates the spectrum, while the short-lived $<1$ ms europium emission after a few milliseconds becomes of vanishing intensity. Similarly, the TRES recorded for $\mathbf{3}$ is dominated by the europium centered emission at short decay times, which is expected when considering the luminescence spectrum in Figure 3. As for $\mathbf{2}$ the short-lived $<1 \mathrm{~ms}$ europium emission disappears in the TRES in the last third of the TRES in Figure 3, highlighted by the band at $700 \mathrm{~nm}\left(\mathrm{Eu}^{5} \mathrm{D}_{0} \rightarrow{ }^{4} \mathrm{~F}_{4}\right)$, resulting in a spectrum originating from terbium centered emission at long decay times. In both TRES the power of the technique can be seen in the bands in the region $580-600 \mathrm{~nm}\left(\mathrm{~Tb}^{5} \mathrm{D}_{4}\right.$ $\left.\rightarrow{ }^{4} \mathrm{~F}_{4}, \mathrm{Eu}{ }^{5} \mathrm{D}_{0} \rightarrow{ }^{4} \mathrm{~F}_{0,1}\right)$ and at $620 \mathrm{~nm}\left(\mathrm{~Tb}^{5} \mathrm{D}_{4} \rightarrow{ }^{4} \mathrm{~F}_{3}, \mathrm{Eu}{ }^{5} \mathrm{D}_{0} \rightarrow{ }^{4} \mathrm{~F}_{2}\right)$. Independent of whether terbium or europium emission dominate this region of the spectrum, the fact that two components with different lifetimes contribute to the emission intensity observed at short decay times (Figure $\mathbf{3}$ ), is realized by cursory inspection of the TRES in Figure 5. 

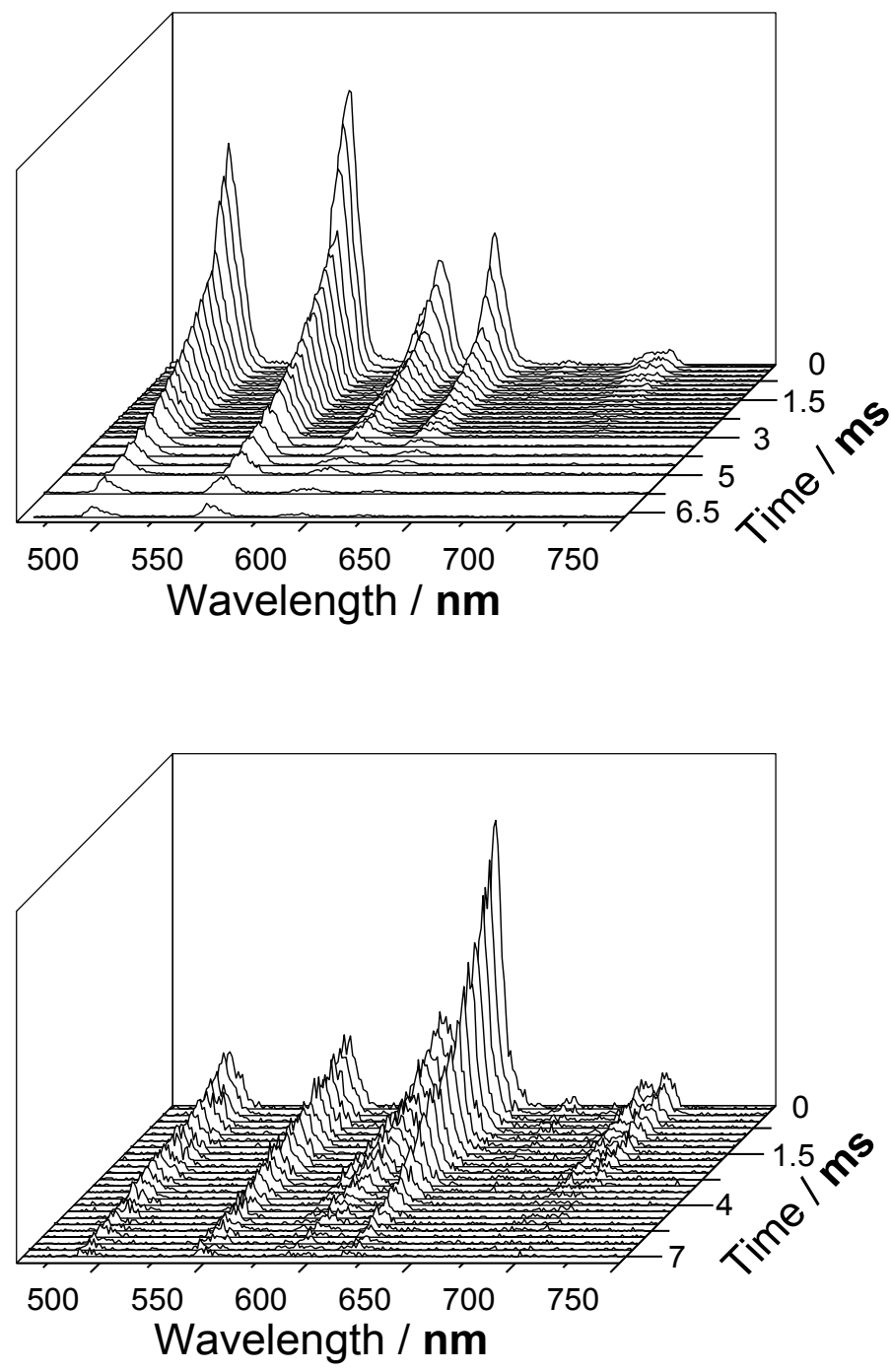

Figure 5. Time resolved emission spectra in methanol of $\mathbf{2}$ (top) and $\mathbf{3}$ (bottom), from $0.1 \mathrm{~ms}$ to $6.5 \mathrm{~ms}$ initial time-delay in methanol.

\section{Luminescence lifetimes in water and $q$}

The luminescence lifetime alone does not allow for conclusions as to which pathway the individual excited state is populated by, but does allow for conclusions as to the degree of quenching of the individual excited states. In combination with the results obtained above, determining the luminescence lifetimes makes it possible to deduce how the observed changes in the photophysical properties between the compounds 2 and $\mathbf{3}$ arise. Furthermore, by comparing the luminescence lifetimes of $\mathbf{2}$ and $\mathbf{3}$ in different solvents, and comparing the properties of the compounds as free molecules and bound to isophthalate, the differences between the two structures become clear.

Free molecules

Table 1 shows the luminescence lifetimes recorded in the emission bands that can be exclusively assigned to either terbium or europium emission $\left(545 \mathrm{~nm}, \mathrm{~Tb}^{5} \mathrm{D}_{4} \rightarrow{ }^{7} \mathrm{~F}_{5} ; 700 \mathrm{~m}, \mathrm{Eu}^{5} \mathrm{D}_{0} \rightarrow{ }^{7} \mathrm{~F}_{4}\right)$ following excitation in the chromophore manifold at $275 \mathrm{~nm}$. The europium centers in compound $\mathbf{1}$ and $\mathbf{2}$ experience very similar 
surroundings, and have identical luminescence lifetimes and $q$ values. The europium centers in $\mathbf{3}$ show a significantly increased luminescence lifetime, due to a significant reduction in $q$ from $q=1.4$ in $\mathbf{1}$ and $\mathbf{2}$ to $q$ $=0.5$ in 3 . The terbium center shows different behavior between the starting material 4 and the compounds $\mathbf{2}$ and $\mathbf{3}$. The luminescence lifetimes are identical for all three systems within error, while $q$ reduces from $q=0.9$ in $\mathbf{4}$ to $q=0.6$ in $\mathbf{2}$ and $\mathbf{3}$, indicating that the face of the DOTA-monoamide terbium binding pocket is more crowded in compounds $\mathbf{2}$ and $\mathbf{3}$ when compared to the starting material $\mathbf{4}$. The bulk of the substituent on the secondary aniline nitrogen in $\mathbf{2}$ is not enough to disrupt the average structure of the two DO3A europium binding pockets, resulting in a similar solvation and degree of quenching of europium in $\mathbf{1}$ and $\mathbf{2}$. In $\mathbf{3}$ there are significantly more bulky substituents on the now tertiary aniline nitrogen, and as a consequence there is a substantial change in solvation around europium, resulting in a much longer luminescence lifetime and a lower $q$. The bulk of the third substituent on the aniline nitrogen in $\mathbf{3}$ does not influence the terbium centered emission, indicating that the terbium complex is positioned in such a way that it is only influenced by the structural unit originating from $\mathbf{1}$, and not by the substituents introduced through the Ugi coupling. This assumption is supported by the results obtained in the emission and excitation spectra above, where the terbium centers in $\mathbf{2}$ and $\mathbf{3}$ have similar behaviors.

Table 1. Luminescence lifetime, number of inner sphere solvent molecules $q$ (Horrocks), and number of inners sphere solvent molecules $\mathrm{n}$ (Kimura) for compounds 1-4 in water and following excitation at $275 \mathrm{~nm}$ (excitation slit: $14 \mathrm{~nm}$, emission slit: 5-14 $\mathrm{nm}$ )

\begin{tabular}{|l|l|l|l|l|l|}
\hline & $\lambda \mathrm{em} / \mathrm{nm}^{a}$ & $\mathbf{1}$ & $\mathbf{2}$ & $\mathbf{3}$ & $\mathbf{4}$ \\
\hline$\tau_{\mathrm{H} 2 \mathrm{O}} / \mathrm{ms}$ & 700 & 0.4 & 0.4 & 0.8 & \\
\hline$\tau_{\mathrm{D} 2 \mathrm{O}} / \mathrm{ms}$ & 700 & 0.9 & 0.9 & 1.7 & \\
\hline$q_{\mathrm{Eu}}$ & & 1.4 & 1.4 & 0.5 & \\
\hline $\mathrm{n}$ Kimura & & 2.2 & 2.2 & 0.9 & \\
\hline$\tau_{\mathrm{H} 2 \mathrm{O}} / \mathrm{ms}$ & 545 & & 1.8 & 1.9 & 1.9 \\
\hline$\tau_{\mathrm{D} 2 \mathrm{O}} / \mathrm{ms}$ & 545 & & 2.6 & 2.9 & 3.4 \\
\hline$q_{\mathrm{Tb}}$ & & & 0.6 & 0.6 & 0.9 \\
\hline n Kimura & & & 1.4 & 1.3 & 1.3 \\
\hline
\end{tabular}

$q$ calculated using $\left.q=\mathrm{A}\left(\tau\left(\mathrm{H}_{2} \mathrm{O}\right)^{-1}-\tau\left(\mathrm{D}_{2} \mathrm{O}\right)^{-1}-\mathrm{B}\right)\right) \mathrm{A}: 5 \mathrm{~ms}(\mathrm{~Tb}), 1.2 \mathrm{~ms}(\mathrm{Eu}) ; \mathrm{B}:-0.06 \mathrm{~ms}^{-1}(\mathrm{~Tb}),-0.25 \mathrm{~ms}^{-1}(\mathrm{Eu})$,

To highlight the importance of controlled experimental conditions, the effect of $\mathrm{pH}$ on the luminescence lifetime of $\mathbf{1}$ was investigated. The results are shown in Table $\mathbf{2}$, and suggest that $\mathrm{pH}$, solvent composition and ionic strength must be identical in all samples if properties such as luminescence lifetime and $q$ are to be compared. Upon changing from $\mathrm{pH} 9$ to 2, the luminescence lifetime is reduced by close to a factor of 2, while $q$ increases by almost a factor of 4 from $q=0.5$ to $q=1.8$. Note that the number of solvent molecules at the lanthanide center as calculated by the Kimura method does not follow the trends reported by $q$, but does register the change in solvation between low and high $\mathrm{pH}$.

Table 2. Effect of $\mathrm{pH} / \mathrm{pD}$ on the luminescence lifetime and on the number of inner sphere solvent molecules $q$ for 1 in water/ $\mathrm{D}_{2} \mathrm{O}$ following $280 \mathrm{~nm}$ excitation.

\begin{tabular}{|l|l|l|l|l|l|l|}
\hline & $\tau_{\mathrm{H} 2 \mathrm{O}} / \mathrm{ms}$ & $+/-$ & $\tau_{\mathrm{D} 2 \mathrm{O}} / \mathrm{ms}$ & $+/-$ & $\mathrm{q}_{\mathrm{Eu}}$ & $\mathrm{n}$ Kimura \\
\hline $\mathrm{pH} \mathrm{2}$ & 0.41 & 0.05 & 1.39 & 0.13 & 1.8 & 2.1 \\
\hline $\mathrm{pH} \mathrm{6.7}$ & 0.38 & 0.03 & 0.92 & 0.04 & 1.6 & 2.3 \\
\hline $\mathrm{pH} \mathrm{9}{ }^{a}$ & 0.68 & & 1.24 & & 0.5 & 1.1 \\
\hline $\mathrm{pH} \mathrm{12.5}$ & 0.61 & 0.04 & 1.37 & 0.06 & 0.8 & 1.3 \\
\hline
\end{tabular}

${ }^{a}$ from reference $[46]^{b} q$ calculated using $\left.q=\mathrm{A}\left(\tau\left(\mathrm{H}_{2} \mathrm{O}\right)^{-1}-\tau\left(\mathrm{D}_{2} \mathrm{O}\right)^{-1}-\mathrm{B}\right)\right) \mathrm{A}: 1.2 \mathrm{~ms}(\mathrm{Eu}) ; \mathrm{B}:-0.25 \mathrm{~ms}^{-1}(\mathrm{Eu}) \cdot \mathrm{n}$ calculated using $n=1.05\left(\tau\left(\mathrm{H}_{2} \mathrm{O}\right)^{-1}-0.44\right.$. (Eu) 


\section{Solvent effects}

The luminescence lifetimes listed in Table $\mathbf{1}$ and Table $\mathbf{2}$ are all measured in aqueous solution. The emission spectra in Figure $\mathbf{3}$ show a large degree of solvatochromism for $\mathbf{3}$ particularly with respect to the ratio of europium to terbium centered emission intensity, while only small changes in the terbium branching ratios of $\mathbf{2}$ were observed. By comparing the luminescence lifetimes of $\mathbf{2}$ and $\mathbf{3}$ in different solvents it is possible to separate the contributions to the increased emission intensity of europium due to solvation, from those due to increased sensitization due to changes in molecular structure. The strong distance dependence $\left(10^{-}\right.$ $\left.r / r^{-6}\right)$ in the energy transfer from the chromophores to the lanthanide center makes the process highly dependent on molecular structure. Considering the contribution from the refractive index changes when going from acetonitrile to water, the rate of spontaneous emission increase by $2.5 \%$,[47] with an additional increase of $2.5 \%$ from water to methanol. This cannot account for the observed changes in the emission spectrum of $\mathbf{3}$ (Figure $\mathbf{3}$ ), which must originate from changes in the solution structure of the molecule.

Table 3. Solvent effects on the luminescence lifetimes of compounds $\mathbf{2}$ and $\mathbf{3}$ following excitation at $\mathbf{2 8 0} \mathrm{nm}$ or $488 \mathrm{~nm}$ (excitation slit: $20 \mathrm{~nm}$, emission slit: $10 \mathrm{~nm}$ ).

\begin{tabular}{|c|l|c|c|c|c|}
\hline & & \multicolumn{2}{|c|}{$\mathbf{2}$} & \multicolumn{2}{c|}{3} \\
\hline & & \multicolumn{2}{|c|}{$\tau / \mathrm{ms}$} & \multicolumn{2}{c|}{$\tau / \mathrm{ms}$} \\
\hline & Ln & $280 \mathrm{~nm}$ & $488 \mathrm{~nm}$ & $280 \mathrm{~nm}$ & $488 \mathrm{~nm}$ \\
\hline \multirow{2}{*}{$\mathrm{H}_{2} \mathrm{O}$} & $\mathrm{Eu}$ & 0.4 & - & 0.8 & - \\
\cline { 2 - 6 } & $\mathrm{Tb}$ & 1.8 & 1.7 & 1.9 & 2.1 \\
\hline \multirow{2}{*}{$\mathrm{CH}_{3} \mathrm{OH}$} & $\mathrm{Eu}$ & 0.4 & - & 1.1 & - \\
\cline { 2 - 6 } & $\mathrm{Tb}$ & 1.7 & 1.4 & 1.4 & 1.6 \\
\hline \multirow{2}{*}{$\mathrm{CH}_{3} \mathrm{CN}$} & $\mathrm{Eu}$ & 0.4 & - & 1.2 & - \\
\cline { 2 - 6 } & $\mathrm{Tb}$ & 1.4 & 1.1 & 2.1 & 2.3 \\
\hline
\end{tabular}

The solvent dependence of the luminescence lifetime of $\mathbf{2}$ and $\mathbf{3}$ is shown in Table $\mathbf{3}$, note that the emission spectra shown in Figure 3 are for $\mathrm{D}_{2} \mathrm{O}, \mathrm{CH}_{3} \mathrm{OH}$ and $\mathrm{CH}_{3} \mathrm{CN}$ solutions. Considering only water, the ratio of europium centered emission to terbium centered emission in $\mathbf{3}$ should be significantly higher than in $\mathbf{2}$ as a consequence of the much longer luminescence lifetime. This is the case, and the increase is the factor of 2 expected from the emission spectrum (i.e. $\phi_{L M}=\tau / \tau_{r} ; \tau_{r}=k_{r}^{-1}$ ). [27] For 2 the luminescence lifetime observed at the europium center is identical in all solvents, and the same is the case for the terbium center although the lifetime in acetonitrile is slightly shorter. That is, the lifetimes and the observed spectra for 2 agree with small changes exclusively due to solvation of the metal center and the refractive index of the solvent. For 3 the luminescence lifetime observed at both lanthanide center varies between solvent systems. Assuming that the symmetry at each lanthanide center is unchanged, the ratio between the lifetime observed for europium and terbium can be used to indicate the origin of the changes in the emission intensity at each lanthanide center. By using this assumption, the ratio between europium and terbium centered emission should be similar in water and acetonitrile, while the ratio should favor europium in methanol due to quenching of the terbium centered emission. This is not what is observed in the spectrum, where the europium emission is greatly increased in acetonitrile, and only slightly so in methanol. Furthermore, as the increase is too large to be accounted for by an increase in lifetime, and as the changes in lifetime do not follow the trend observed in the spectra, it must be concluded that the observed changes are primarily due to increased energy transfer from the sensitizing chromophores as a result of variations in the molecular structure. 


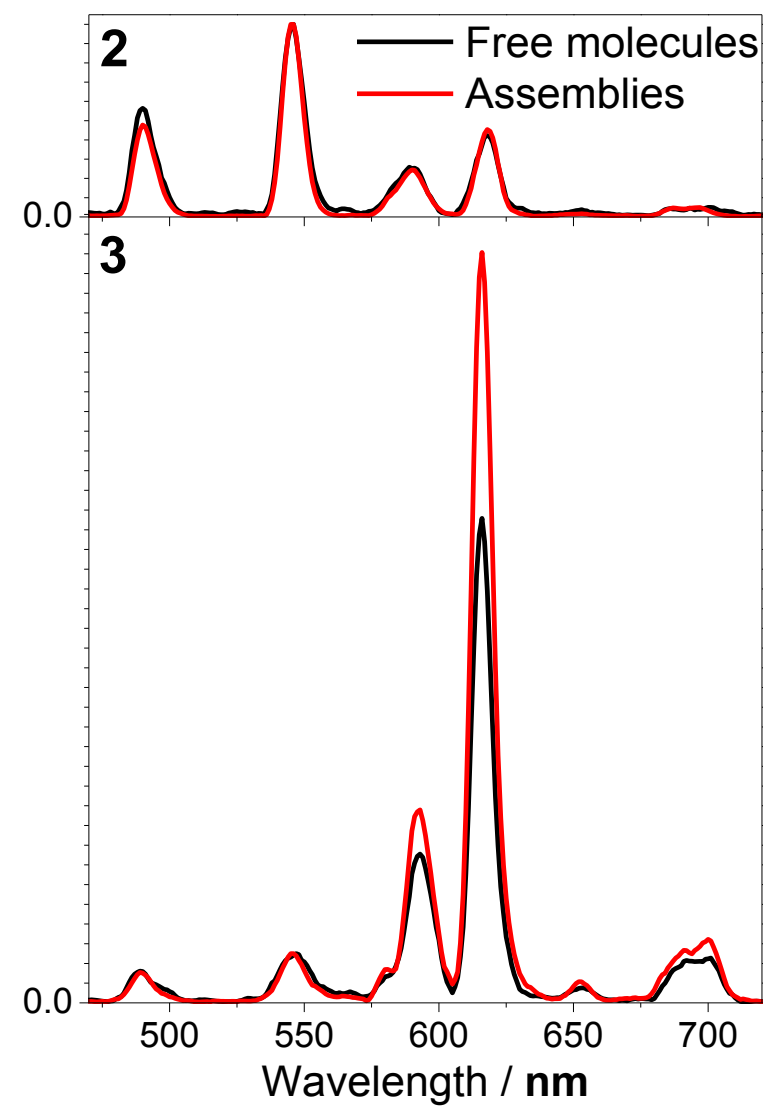

Figure 6. Normalized luminescence emission spectra of $\mathbf{2}$ and $\mathbf{3}$ in methanol with and without isophthalate, recorded with a $5 \mathrm{~nm}$ emission slit following $280 \mathrm{~nm}$ excitation (excitation slit: $20 \mathrm{~nm}$, delay: $0.2 \mathrm{~ms}$, window: $3 \mathrm{~ms}$ ). The spectra are on the same scale and are normalized at $545 \mathrm{~nm}$.

Direct excitation of terbium gives rise to a significantly different average lifetime than that observed following sensitized excitation. We hypothesize that this is due to the existence of two distinctly different molecular conformations, one closed conformation where sensitization of terbium is possible via the aromatic rings of compounds $\mathbf{2}$ and $\mathbf{3}$, and one open conformation where this process does not occur. The differences in the observed lifetimes are thus a result of the different quenching pathways operating in the two conformations.[41] As the luminescence lifetime data are the result of the weighted average over the molecular conformations that the individual molecules adopt during the millisecond excited state lifetime, we cannot quantify our observation. The excitation process is instantaneous, and demonstrates that two significantly different conformations of $\mathbf{2}$ and $\mathbf{3}$ are present in solution, and that these have different photophysical properties.

\section{Assemblies}

Changes in the solvent can change the effective chromophore density, see above. The same effect can be realized in a self-assembly process, where isophthalic acid is bound in the binding pocket created by the $\alpha, \alpha^{\prime}$-bis(Eu.DO3A)- $m$-xylene motif.[46, 48-50] Figure 6 shows the changes in the spectral shape upon binding of isophthalate to compound $\mathbf{2}$ and $\mathbf{3}$ in methanol; the total emission intensity increases significantly for both complexes,[22] but the increase for $\mathbf{2}$ is not accompanied by any changes in the appearance of the spectrum.[22] For 3 the overall increase in emission intensity occurs with a clear 
preference for generating europium centered excited states,[22] which can be seen by the increased europium centered emission in comparison to terbium centered emission in Figure 6.

Table 4. Luminescence lifetimes before and after the binding of isophthalate in methanol.

\begin{tabular}{llllll}
\hline \multicolumn{2}{c}{$\tau_{\mathrm{MeOH}} / \mathrm{ms}$} & \multicolumn{2}{c}{$\mathbf{2}$} & \multicolumn{2}{c}{ Final } \\
$\lambda_{\mathrm{ex}} / \mathrm{nm}$ & $\lambda_{\mathrm{em}} / \mathrm{nm}$ & Initial & Final & Initial & 1.5 \\
275 & 545 & 1.7 & 1.4 & 1.8 & 1.0 \\
\hline
\end{tabular}

Table $\mathbf{4}$ shows the lifetime changes upon binding isophthalate to $\mathbf{2}$ and $\mathbf{3}$. The europium lifetime is unchanged, while the terbium excited state lifetime is decreased in both cases. This observation can be rationalized by considering the conformational space available to the molecules, and assuming an increase in the population of molecules that are in a configuration with increased quenching of the terbium center.[22] That is, binding of isophthalate in the $\alpha, \alpha$-bis(Eu.DO3A)- $m$-xylene binding pocket forces a significant change in conformation of the entire molecule.

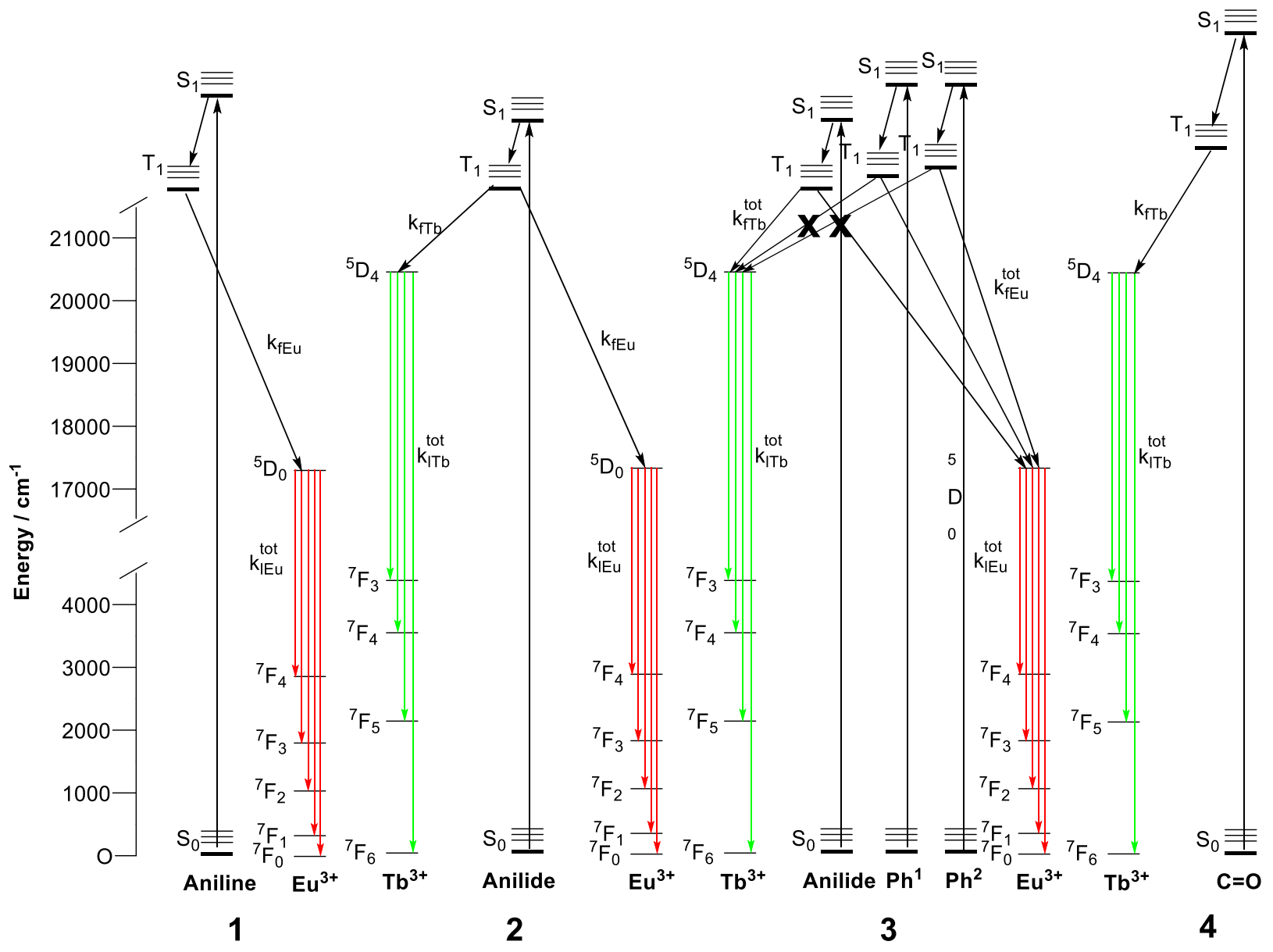

Figure 7. Partial Jablonski diagrams showing the possible sensitization pathways for $\mathbf{1 , 2 , 3}$ and $\mathbf{4}$.

\section{Conclusion}

Figure 7 shows the excited state processes responsible for the lanthanide luminescence observed from the investigated complexes 1, 2, 3 and $\mathbf{4}$. The data reported here demonstrate that by comparing these four 
systems we can separate the processes originating from differences in molecular constitution from those originating in changes in molecular conformation. We found that changes in the molecular constitution do not inevitably correlate directly to luminescence observed from a given molecule. Specifically, we show that simply increasing the chromophore density in a given molecular framework does not necessarily facilitate an increase in the excited state population of a given lanthanide center in that structure, but may actually decrease the observed emission if the lanthanide center is excluded from the conformational isomers giving rise to efficient formation of the lanthanide excited state. That is, some of the processes shown in Figure $\mathbf{7}$ do not occur, e.g. population of the terbium center from the phenyl chromophores in compound 3 (see Figure 4). Our observations do not show evidence for Ln to Ln' energy transfer in these systems, indicating that close contact of the lanthanide centers are not possible.[51]

Comparing the photophysical properties of compounds $\mathbf{2}$ and $\mathbf{3}$, a dramatic effect can be seen in the response to changes in solvent or in the result of binding an analyte. While the properties of $\mathbf{2}$ are essentially unchanged, the luminescence observed from $\mathbf{3}$ exhibits pronounced solvatochromism and spectral changes upon binding of analytes. Thus, we must conclude that predicting the properties of larger lanthanide containing molecules is exceedingly difficult, as small changes may alter the general behavior of the entire molecule significantly. For the structures investigated here, the pivotal point where the properties become unpredictable occurs when the central aniline nitrogen goes from having two to three substituents.

\section{Acknowledgements}

The authors thank the University of Oxford, Christ Church (MT), the European Research Council FP7/20072013/ERC-Grant Agreement Number 267426 (OAB), the CRUK \& EPSRC Cancer Imaging Centre in Oxford (LRH), the Carlsberg Foundation (TJS), and Keble College (TJS, SF) for financial support.

\section{References}

[1] A. Zaim, S.V. Eliseeva, L. Guenee, H. Nozary, S. Petoud, C. Piguet, Lanthanide-to-lanthanide energy-transfer processes operating in discrete polynuclear complexes: can trivalent europium be used as a local

structural probe?, Chem. Eur. J., 20 (2014) 12172-12182.

[2] L. Aboshyan-Sorgho, H. Nozary, A. Aebischer, J.C. Bunzli, P.Y. Morgantini, K.R. Kittilstved, A. Hauser, S.V. Eliseeva, S. Petoud, C. Piguet, Optimizing millisecond time scale near-infrared emission in polynuclear chrome(III)-lanthanide(III) complexes, Journal of the American Chemical Society, 134 (2012) 12675-12684.

[3] J.C. Bunzli, C. Piguet, Taking advantage of luminescent lanthanide ions, Chemical Society reviews, 34 (2005) 1048-1077. [4] Y. Liu, D. Tu, H. Zhu, X. Chen, Lanthanide-doped luminescent nanoprobes: controlled synthesis, optical spectroscopy, and bioapplications, Chemical Society reviews, 42 (2013) 6924-6958. 
[5] L.D. Sun, Y.F. Wang, C.H. Yan, Paradigms and challenges for bioapplication of rare earth upconversion luminescent nanoparticles: small size and tunable emission/excitation spectra, Acc Chem Res, 47 (2014) 1001-1009.

[6] S. Gai, C. Li, P. Yang, J. Lin, Recent progress in rare earth micro/nanocrystals: soft chemical synthesis, luminescent properties, and biomedical applications, Chem Rev, 114 (2014) 2343-2389.

[7] W.T. Carnall, G.L. Goodman, K. Rajnak, R.S. Rana, A systematic analysis of the spectra of the lanthanides doped into single crystal LaF3 The Journal of chemical physics, 90 (1989) 3443-3457.

[8] W.T. Carnall, Chapter 24 The absorption and fluorescence spectra of rare earth ions in solution, in: Karl A. Gschneidner, Jr., E. LeRoy (Eds.) Handbook on the Physics and Chemistry of Rare Earths, Elsevier, 1979, pp. 171-208.

[9] W.T. Carnall, Electronic Energy Levels of the Trivalent Lanthanide Aquo Ions. II. Gd3+, The Journal of chemical physics, 49 (1968) 4443.

[10] W.T. Carnall, Electronic Energy Levels of the Trivalent Lanthanide Aquo lons. III. Tb3+, The Journal of chemical physics, 49 (1968) 4447. [11] W.T. Carnall, Electronic Energy Levels of the Trivalent Lanthanide Aquo lons. IV. Eu3+, The Journal of chemical physics, 49 (1968) 4450. [12] W.T. Carnall, Electronic Energy Levels in the Trivalent Lanthanide Aquo lons. I. Pr3+, Nd3+, Pm3+, Sm3+, Dy3+, Ho3+, Er3+, and Tm3+, The Journal of chemical physics, 49 (1968) 4424.

[13] D. Parker, Excitement in f block: structure, dynamics and function of nine-coordinate chiral lanthanide complexes in aqueous media, Chemical Society reviews, 33 (2004) 156-165.

[14] D. Parker, R.S. Dickins, H. Puschmann, C. Crossland, J.A.K. Howard, Being Excited by Lanthanide Coordination Complexes: Aqua Species, Chirality, Excited-State Chemistry, and Exchange Dynamics, Chem. Rev., 102 (2002) 1977-2010.

[15] A. Beeby, I.M. Clarkson, R.S. Dickins, S. Faulkner, D. Parker, L. Royle, A.S. de Sousa, J.A.G. Williams, M. Woods, Non-radiative deactivation of the excited states of europium, terbium and ytterbium complexes by proximate energy-matched $\mathrm{OH}, \mathrm{NH}$ and $\mathrm{CH}$ oscillators: an improved 
luminescence method for establishing solution hydration states, Journal of the Chemical Society, Perkin Transactions 2, (1999) 493-504.

[16] J.-C.G. Bünzli, Lanthanide coordination chemistry: From old concepts to coordination polymers, Journal of Coordination Chemistry, (2014) 1-45. [17] T.J. Sørensen, M. Tropiano, O.A. Blackburn, J.A. Tilney, A.M. Kenwright, S. Faulkner, Preparation and study of an $f, f, f^{\prime}, f^{\prime \prime}$ covalently linked tetranuclear hetero-trimetallic complex - a europium, terbium, dysprosium triad, Chem Commun (Camb), 49 (2013) 783-785. [18] M. Main, J.S. Snaith, M.M. Meloni, M. Jauregui, D. Sykes, S. Faulkner, A.M. Kenwright, Using the Ugi multicomponent condensation reaction to prepare families of chromophore appended azamacrocycles and their complexes, Chem Commun (Camb), (2008) 5212-5214.

[19] M. Tropiano, N.L. Kilah, M. Morten, H. Rahman, J.J. Davis, P.D. Beer, S. Faulkner, Reversible luminescence switching of a redox-active ferroceneeuropium dyad, J. Am. Chem. Soc., 133 (2011) 11847-11849.

[20] M. Tropiano, C.J. Record, E. Morris, H.S. Rai, C. Allain, S. Faulkner, Synthesis and Spectroscopic Study of $d-f$ Hybrid Lanthanide Complexes Derived from triazolylDO3A, Organometallics, 31 (2012) 5673-5676. [21] M. Jauregui, W.S. Perry, C. Allain, L.R. Vidler, M.C. Willis, A.M. Kenwright, J.S. Snaith, G.J. Stasiuk, M.P. Lowe, S. Faulkner, Changing the local coordination environment in mono- and bi- nuclear lanthanide complexes through "click" chemistry, Dalton transactions, (2009) 62836285.

[22] M. Tropiano, O.A. Blackburn, J.A. Tilney, L.R. Hill, M.P. Placidi, R.J. Aarons, D. Sykes, M.W. Jones, A.M. Kenwright, J.S. Snaith, T.J. Sørensen, S. Faulkner, Using remote substituents to control solution structure and anion binding in lanthanide complexes, Chem Eur J, 19 (2013) 1656616571.

[23] P. Hänninen, H. Härmä, Lanthanide Luminescence, Springer, Heidelberg, 2011.

[24] A. de Bettencourt-Dias, Introduction to Lanthanide Ion Luminescence, in: Luminescence of Lanthanide lons in Coordination Compounds and Nanomaterials, John Wiley \& Sons Ltd, 2014, pp. 1-48. 
[25] D.E. Morris, A. de Bettencourt-Dias, Spectroscopic Techniques and Instrumentation, in: Luminescence of Lanthanide lons in Coordination Compounds and Nanomaterials, John Wiley \& Sons Ltd, 2014, pp. 49-76. [26] W.D. Horrocks, D.R. Sudnick, Lanthanide ion probes of structure in biology. Laser-induced luminescence decay constants provide a direct measure of the number of metal-coordinated water molecules, Journal of the American Chemical Society, 101 (1979) 334-340.

[27] N.J. Turro, Modern Molecular Photochemistry University Science Books Sausalito, 1991.

[28] B. Valeur, Molecular Fluorescence: Principles and Applications, WileyVCH, Weinheim, 2002.

[29] T. Kimura, Y. Kato, Luminescence Study on Determination of the Hydration Number of Sm(lii) and Dy(lii), J Alloy Compd, 225 (1995) 284287.

[30] J. Scholten, G.A. Rosser, J. Wahsner, N. Alzakhem, C. Bischof, F. Stog, A. Beeby, M. Seitz, Anomalous reversal of C-H and C-D quenching efficiencies in luminescent praseodymium cryptates, Journal of the American Chemical Society, 134 (2012) 13915-13917.

[31] A. Beeby, S. Faulkner, Luminescence from neodymium(III) in solution, Chem Phys Lett, 266 (1997) 116-122.

[32] S. Faulkner, A. Beeby, M.C. Carrie, A. Dadabhoy, A.M. Kenwright, P.G. Sammes, Time-resolved near-IR luminescence from ytterbium andneodynium complexes of the Lehn cryptand, Chemical Communications, (2001).

[33] Y. Hasegawa, K. Murakoshi, Y. Wada, S. Yanagida, J.-H. Kim, N. Nakashima, T. Yamanaka, Enhancement of luminescence of $\mathrm{Nd} 3+$ complexes with deuterated hexafluoroacetylacetonato ligands in organic solvent, Chem Phys Lett, 248 (1996) 8-12.

[34] C. Doffek, J. Wahsner, E. Kreidt, M. Seitz, Breakdown of the energy gap law in molecular lanthanoid luminescence: the smallest energy gap is not universally relevant for nonradiative deactivation, Inorganic chemistry, 53 (2014) 3263-3265. 
[35] T. Kimura, R. Nagaishi, Y. Kato, Z. Yoshida, Luminescence study on preferential solvation of Europium(III) in water/non-aqueous solvent mixtures, J Alloy Compd, 323 (2001) 164-168.

[36] T. Kimura, R. Nagaishi, Y. Kato, Z. Yoshida, Luminescence study on solvation of americium(III), curium(III) and several lanthanide(III) ions in nonaqueous and binary mixed solvents, Radiochim Acta, 89 (2001) 125130.

[37] T. Kimura, Y. Kato, Luminescence study on hydration states of lanthanide(III)-polyaminopolycarboxylate complexes in aqueous solution, J Alloy Compd, 275-277 (1998) 806-810.

[38] T. Kimura, Y. Kato, Luminescence study on determination of the innersphere hydration number of Am(III) and Nd(III), J Alloy Compd, 271 (1998) 867-871.

[39] T. Kimura, Y. Kato, Luminescence study on the inner-sphere hydration number of lanthanide(III) ions in concentrated aqueous salt solutions in fluid and frozen states, J Alloy Compd, 278 (1998) 92-97.

[40] T. Kimura, G.R. Choppin, Y. Kato, Z. Yoshida, Determination of the hydration number of $\mathrm{Cm}(\mathrm{III})$ in various aqueous solutions, Radiochim Acta, 72 (1996) 61-64.

[41] T.J. Sørensen, A.M. Kenwright, S. Faulkner, Bimetallic lanthanide complexes that display a ratiometric response to oxygen concentrations, Chemical Science, 6 (2015) 2054-2059.

[42] D. Parker, J.A.G. Williams, Luminescence behaviour of cadmium, lead, zinc, copper, nickel and lanthanide complexes of octadentate macrocyclic ligands bearing naphthyl chromophores, Journal of the Chemical Society, Perkin Transactions 2, (1995) 1305-1314.

[43] R. Hueting, M. Tropiano, S. Faulkner, Exploring energy transfer between pyrene complexes and europium ions - potential routes to oxygen sensors, RSC Adv., 4 (2014) 44162-44165.

[44] Z. Liao, M. Tropiano, K. Mantulnikovs, S. Faulkner, T. Vosch, T. Just Sørensen, Spectrally resolved confocal microscopy using lanthanide centred near-IR emission, Chemical Communications, 51 (2015) 23722375. 
[45] R C Benson, R A Meyer, G. M E Zaruba, M. McKhann, Cellular autofluorescence--is it due to flavins? , J Histochem Cytochem, 27 (1979) 44-48

[46] L.R. Hill, T.J. Sørensen, O.A. Blackburn, A. Brown, P.D. Beer, S. Faulkner, Self-assembly between dicarboxylate ions and binuclear europium complexes: moving to water-pH dependence and effects of buffers, Dalton transactions, 42 (2013) 67-70.

[47] S.J. Strickler, R.A. Berg, Relationship between absorption intensity and fluorescence lifetime of molecules, J. Chem. Phys., 37 (1962) 814-\&. [48] T.J. Sørensen, L.R. Hill, J.A. Tilney, O.A. Blackburn, M.W. Jones, M. Tropiano, S. Faulkner, Self-Assembly between Dicarboxylate Ions and Dinuclear Lanthanide Complexes: A Surprisingly Complicated Problem, European Journal of Inorganic Chemistry, 2014 (2014) 2520-2528. [49] J.A. Tilney, T.J. Sørensen, B.P. Burton-Pye, S. Faulkner, Self-assembly between dicarboxylate ions and a binuclear europium complex: formation of stable adducts and heterometallic lanthanide complexes, Dalton transactions, 40 (2011) 12063-12066.

[50] L.R. Hill, O.A. Blackburn, M.W. Jones, M. Tropiano, T.J. Sørensen, S. Faulkner, Ternary self-assemblies in water: forming a pentanuclear ReLn4 assembly by association of binuclear lanthanide binding pockets with facRe(CO)3(dinicotinate)2Cl, Dalton transactions, 42 (2013) 16255-16258. [51] A. Nonat, M. Regueiro-Figueroa, D. Esteban-Gomez, A. de Blas, T. Rodriguez-Blas, C. Platas-Iglesias, L.J. Charbonniere, Definition of an intramolecular Eu-to-Eu energy transfer within a discrete [EU2L] complex in solution, Chemistry, 18 (2012) 8163-8173. 